\title{
Ezetimibe therapy: mechanism of action and clinical update
}

\author{
This article was published in the following Dove Press journal: \\ Vascular Health and Risk Management \\ 2 July 2012 \\ Number of times this article has been viewed
}

\author{
Binh An P Phan' \\ Thomas D Dayspring ${ }^{2}$ \\ Peter $\mathrm{P}$ Toth ${ }^{3}$ \\ 'Division of Cardiology, \\ Loyola University Medical Center, \\ Maywood, IL, USA; '²Foundation for \\ Health Improvement and Technology, \\ Wayne, NJ, USA; ${ }^{3} \mathrm{CGH}$ Medical \\ Center, Sterling, IL, USA
}

\begin{abstract}
The lowering of low-density lipoprotein cholesterol (LDL-C) is the primary target of therapy in the primary and secondary prevention of cardiovascular events. Although statin therapy is the mainstay for LDL-C lowering, a significant percentage of patients prescribed these agents either do not achieve targets with statin therapy alone or have partial or complete intolerance to them. For such patients, the use of adjuvant therapy capable of providing incremental LDL-C reduction is advised. One such agent is ezetimibe, a cholesterol absorption inhibitor that targets uptake at the jejunal enterocyte brush border. Its primary target of action is the cholesterol transport protein Nieman Pick C1 like 1 protein. Ezetimibe is an effective LDL-C lowering agent and is safe and well tolerated. In response to significant controversy surrounding the use and therapeutic effectiveness of this drug, we provide an update on the biochemical mechanism of action for ezetimibe, its safety and efficacy, as well as the results of recent randomized studies that support its use in a variety of clinical scenarios.
\end{abstract}

Keywords: bile, coronary artery disease, ezetimibe, low-density lipoprotein cholesterol, Nieman pick $\mathrm{C} 1$ like 1 protein, statin

\section{Introduction}

The association between elevated serum cholesterol levels and risk of cardiovascular disease has been well established through a number of epidemiologic studies, such as the Framingham Heart Study and the Seven Countries Study. ${ }^{1,2}$ Multiple randomized controlled trials over the past two decades have consistently shown that treatment with 3-hydroxy-3-methyl-glutaryl coenzyme A (HMG-CoA) reductase inhibitors (statins) in dyslipidemic patients with and without established vascular disease effectively lowers low-density lipoprotein cholesterol (LDL-C) levels and reduces major cardiovascular events. $^{3-7}$ Based upon these lines of evidence, the National Cholesterol Education Program (NCEP) through the Adult Treatment Panel (ATP) III has recommended reducing LDL-C levels as the primary goal and supports the use of statins as the initial preferred therapy. ${ }^{8}$ Recent trials have suggested that more aggressive lowering of LDL-C to levels of $<70 \mathrm{mg} / \mathrm{dL}$ may result in incremental cardiovascular benefit. ${ }^{9-11}$ Therefore, ATP III was updated to include an optional LDL-C goal of $<70 \mathrm{mg} / \mathrm{dL}$ in very high-risk patients that have established cardiovascular disease with multiple cardiac risk factors. ${ }^{12}$

Despite growing evidence supporting a lower-is-better approach for LDL-C, treatment with statin therapy alone may not be sufficient to achieve optimal LDL-C targets, with some patients requiring greater than a $50 \%$ reduction. ${ }^{13}$ Institutional surveys have shown that only two-thirds of vascular disease patients are at an LDL-C goal of 
$<100 \mathrm{mg} / \mathrm{dL}$ and less than a third of very high-risk patients are able to reach an LDL-C goal of $<70 \mathrm{mg} / \mathrm{dL} .{ }^{14,15}$ Based upon these treatment failures, combination therapies using multiple cholesterol-lowering agents including ezetimibe in addition to statin therapy have been investigated. ${ }^{16,17}$ While ATP III recommends statin therapy as the first-line agent for the treatment of elevated LDL-C, alternative therapies such as ezetimibe, niacin, bile-acid sequestrants, and ileal bypass surgery can also effectively lower LDL-C. ${ }^{17-20} \mathrm{~A}$ recent meta-analysis has shown that these nonstatin-based treatments can lower cardiac events similar to statin therapies, with an equivalent observed relationship between degree of LDL-C lowering and reduction in coronary heart disease (CHD) risk. ${ }^{21}$ These data suggest that the addition of these therapies to a background of statin treatment may produce an incremental lowering of LDL-C, and possibly result in a further reduction in cardiovascular events.

Ezetimibe inhibits intestinal and biliary cholesterol absorption and can significantly lower LDL-C and nonhighdensity lipoprotein cholesterol (non-HDL-C, defined as total cholesterol minus high-density lipoprotein cholesterol) when used alone or in combination with statin therapy. ${ }^{22}$ Despite the established cholesterol-lowering benefits of ezetimibe, significant controversy exists with respect to ezetimibe's vascular and clinical benefit, particularly in light of the Ezetimibe and Simvastatin in Hypercholesterolemic Enhances Atherosclerosis Regression (ENHANCE) trial, which showed no difference in carotid atherosclerosis burden as measured by carotid intima-media thickness (CIMT) in patients with heterozygous familial hypercholesterolemia who were treated with simvastatin plus either ezetimibe or placebo. ${ }^{17,23}$ Based upon this controversy, some providers eliminated or reserved the use of ezetimibe as a last-line agent in lipid management. This review aims to detail the biological mechanisms, lipid effects, and safety of ezetimibe treatment and discuss the vascular and clinical outcomes data that may impact the use of ezetimibe in clinical practice.

\section{Mechanism of action}

Circulating plasma levels of cholesterol are derived from two primary sources: cholesterol production from the liver and peripheral tissues, and the absorption of dietary and biliary cholesterol in the gastrointestinal tract (Figure 1). ${ }^{24,25}$ Cholesterol synthesis begins with the conversion of acetyl-CoA to mevalonate, a reaction catalyzed by the enzyme HMG-CoA reductase. ${ }^{26}$ Cholesterol synthesized by hepatocytes undergoes esterification by acyl-CoA acyl transferase (ACAT) and is incorporated into apolipoprotein
B (ApoB)-containing lipoproteins such as very-low-density lipoprotein (VLDL) via microsomal transfer protein. ${ }^{27,28}$ Subsequent modification of VLDL with hydrolysis of triglycerides by the enzymes lipoprotein lipase and hepatic lipase produces intermediate-density lipoprotein (IDL) and LDL. The transfer of cholesterol from the peripheral tissues to the liver is mediated by HDL. ${ }^{29}$ Nascent pre- $\beta$ HDL particles accept free cholesterol from peripheral tissues via ATP-binding cassette transporter A1 (ABCA1). The cholesterol undergoes subsequent esterification by lecithincholesterol acetyltransferase. The esterified cholesterol moves into the hydrophobic core of the HDL particle, and as the particles become progressively more lipidated, they mature and become progressively larger and more spherical. The cholesteryl esters in these mature HDL particles can be removed from the circulation by hepatic scavenger receptor BI or undergo transfer of cholesterol to apolipoprotein B-containing lipoproteins such as LDL and IDL via the activity of cholesteryl ester transfer protein. ${ }^{30}$ The liver clears LDL particles from the circulation by the LDL receptor and the LDL receptor-related protein. ${ }^{27,28}$

Intestinal cholesterol absorption, occurring primarily in the duodenum and proximal jejunum, can also contribute to serum cholesterol levels. ${ }^{31,32}$ Dietary intake provides about a quarter of the cholesterol entering the intestinal lumen, while the remaining three-quarters are derived from biliary cholesterol excretion from the liver. A distinction must be drawn between cholesterol entry into enterocytes and systemic cholesterol absorption, which refers to the appearance of cholesterol within lymphatic vessels, as not all of the cholesterol that makes its way into enterocytes will be absorbed into plasma. Intestinal cholesterol absorption is a complex process involving incorporation of free cholesterol, the majority of which is of biliary origin, into mixed biliary micelles, and the subsequent delipidation of micelles via intestinal enterocyte membrane sterol influx transporters. ${ }^{33}$ Once in the enterocyte, free cholesterol can be effluxed to ApoA-1, prebeta HDL, or ApoE, esterified by ACAT into cholesteryl ester for incorporation into ApoB48-containing chylomicrons, or effluxed back to the gut lumen by $\mathrm{ABC}$ transporters G5 and G8. Genetic mutations in ABCG5 and ABCG8 proteins result in sitosterolemia, which is associated with an increase in phytosterol accumulation and intestinal cholesterol absorption resulting in significantly elevated plasma cholesterol and plant sterol levels and clinical development of early atherosclerotic heart disease. ${ }^{34-36}$ After secretion into the lymphatic system and drainage via the thoracic duct, chylomicrons and their remnants are 


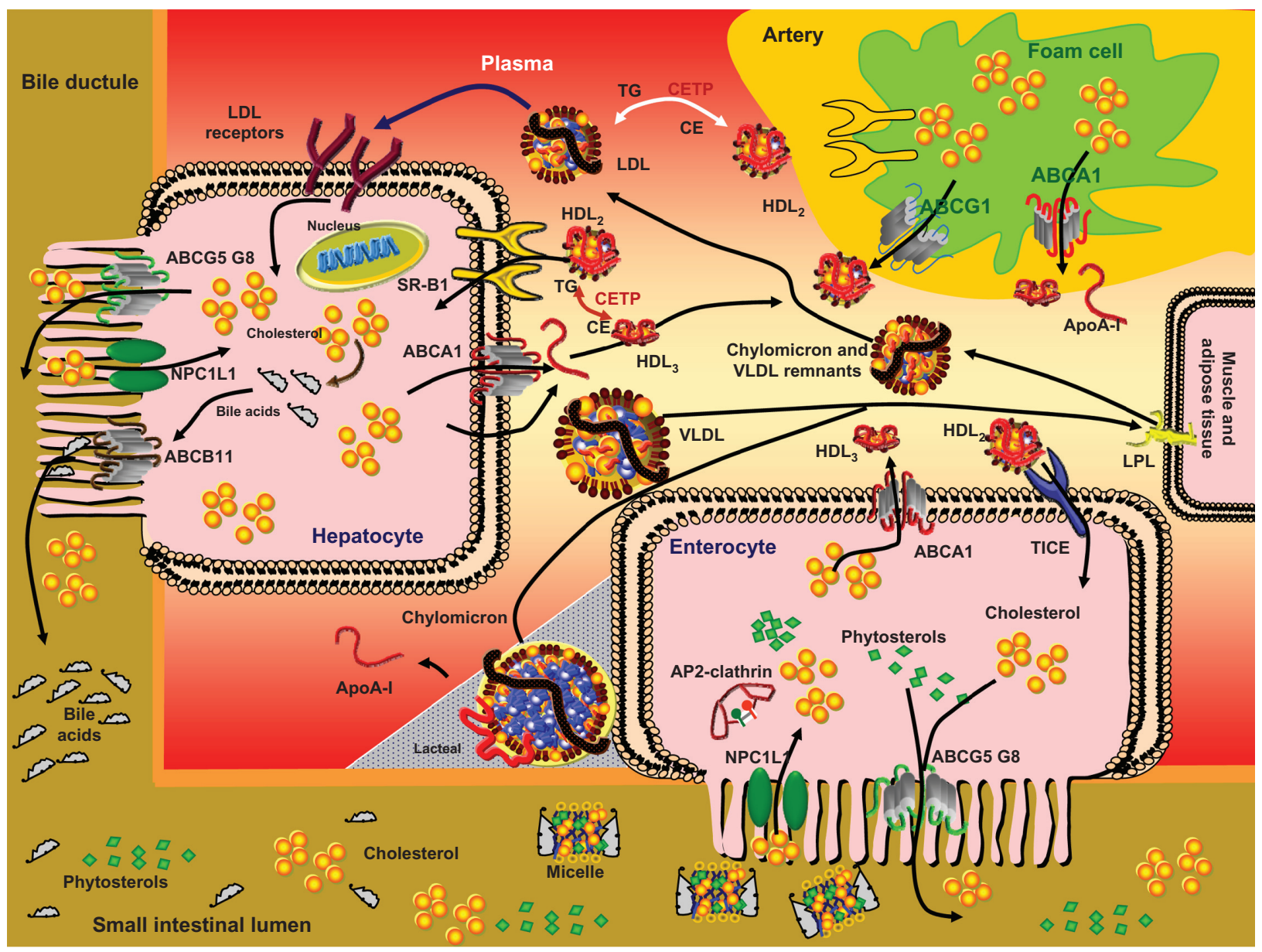

Figure I Lipid and lipoprotein metabolism.

Notes: Cholesterol, phytosterols and other lipids enter biliary micelles and are internalized via the NPCILI protein and the AP2/clathrin complex. Cholesterol can also reenter hepatocytes from the bile via canalicular NPCILI. Nearly all phytosterols and some cholesterol are returned to the gut lumen or to the bile from hepatocytes via $A B C G 5$ and $A B C G 8$. Cholesterol can be converted in hepatocytes to primary bile acids, which are effluxed to the bile via $A B C B I I$. ApoA-I is secreted by the liver or enterocyte or enters plasma on a chylomicron. VLDLs and chylomicrons traffic TG to muscle and adipocyte tissues. During lipolysis, surface phospholipids as well as fatty acids from the TG are also released: the resultant chylomicron remnant is cleared by the liver and the VLDL is converted to IDL, most of which are cleared by LDL receptors in the liver but some undergo additional lipolysis and form LDLs. During their plasma residence time the ApoB particles utilizing CETP exchange TG for CE with HDL particles. Smaller HDLs are lipidated at ABCAI, and larger HDLs at ABCGI or SR BI. Larger HDLs can be delipidated by SR BI at the liver, on adipocytes, or in steroidogenic tissues.

Abbreviations: ABCAI, ATP-binding cassette transporter AI (cholesterol efflux); ABCGI, ATP-binding cassette transporter (cholesterol efflux); ABCG5, ABCG8, ATPbinding cassette transporters G5 and G8 (sterol efflux); ABCBI I, ATP-binding cassette transporter BI I (bile export pump); AP2, adaptor protein 2; ApA, apolipoprotein A; $\mathrm{CE}$, cholesteryl ester; CETP, cholesteryl ester transfer protein; $\mathrm{HDL}_{2}$, larger $\mathrm{HDL}$ species; $\mathrm{HDL}_{3}$, smaller HDL species; IDL, intermediate-density lipoprotein; LPL, lipoprotein lipase; NPCILI, Niemann-Pick CI-like I protein; SR BI, scavenger receptor BI; TG, triglyceride; TICE, transintestinal cholesterol efflux (putative receptor); VLDL, very low-density lipoprotein.

cleared from the circulation by the liver. The triglycerides and cholesterol esters derived from chylomicrons can be repackaged into VLDL and secreted.

In 2004, Altmann et al reported the discovery of the Niemann-Pick C1-like 1 protein (NPC1L1) as the human sterol transport protein that was expressed at the enterocyte/ gut lumen (apical) as well as the hepatobiliary (canalicular) interface. ${ }^{37} \mathrm{NPC} 1 \mathrm{~L} 1$ has a sterol-sensing domain, which is a region consisting of around 180 amino acids that form five predicted membrane-spanning helices with short intervening loops. ${ }^{38,39}$ Current evidence points to the NPC1L1 protein working in conjunction with the adaptor protein 2
(AP2) complex and clathrin to facilitate internalization of free cholesterol into the enterocyte (Figure 2). AP2 is a classical AP that facilitates the internalization of molecules into cells, such as cholesterol entering clathrin-coated pits. The AP2 complex consists of four proteins forming a core and appendage domains. The core carries cholesterol, and the appendage or "ears" bind to clathrin, which has a triskelion shape (three interlocked spirals) composed of three heavy chains and three light chains, which align to form small vesicles capable of internalizing cholesterol. ${ }^{40}$ Cholesterol in the gut lumen or bile incorporates into the cell membrane, where it can bind to the sterol-sensing domain of 


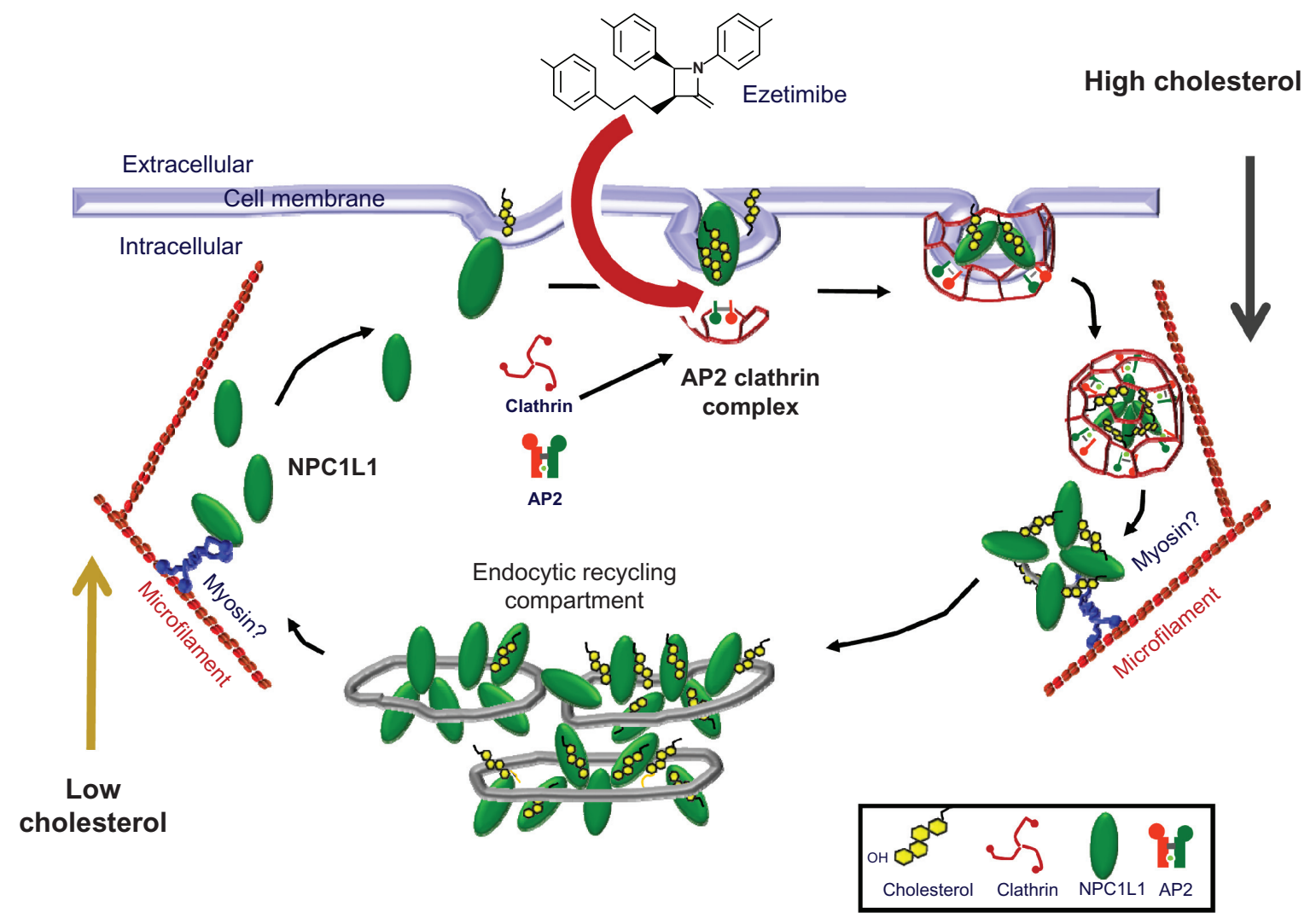

Figure 2 Effect of ezetimibe on NPCILI-mediated internalization of cholesterol.

Notes: NPCILI protein recycles between the plasma cell membrane and endocytic recycling compartment. When the extracellular cholesterol concentration is high, cholesterol is incorporated into the cell membrane and is sensed by cell surface-localized NPCILI. NPCILI and cholesterol are then internalized together through clathrin/ AP2-mediated endocytosis and transported along microfilaments to the ERC in vesicles. The ERC is where cholesterol and NPCILI are stored. When the intracellular cholesterol level is low, ERC-localized NPCILI moves back to the PM along microfilaments in order to absorb cholesterol. Ezetimibe hinders the interaction of the NPCILI/ cholesterol complex with the AP2-clathrin complex.

Copyright @ 2008, Elsevier. Adapted with permission from Ge L, Wang J, Qi W, et al. The cholesterol absorption inhibitor ezetimibe acts by blocking the sterol-induced internalization of NPCILI. Cell Metab. 2008;7:508-519.41

Abbreviations: AP2, adaptor protein 2; ERC, endocytic recycling compartment; NPCILI, Niemann-Pick CI-like I protein; PM, plasma membrane.

NPC1L1. The NPC1L1/cholesterol complex is internalized or endocytosed by joining to AP2 clathrin, creating a vesicle complex that then translocates with the help of myosin along microfilaments in the cytosol to a storage endosome called the endocytic recycling compartment. When intracellular cholesterol becomes low the NPC1L1 is released from the endocytic recycling compartment and traffics back along microfilaments to the cell membrane. ${ }^{41}$

Serum cholesterol levels are regulated based upon an interactive relationship between hepatic cholesterol production and intestinal cholesterol absorption. ${ }^{42}$ Statin therapy reduces serum LDL-C by inhibiting hepatic cholesterol production through inhibition of the rate-limiting step in cholesterol synthesis catalyzed by HMG-CoA reductase. ${ }^{26}$ In response to the decrease in hepatic cholesterol production, the liver upregulates hepatic LDL receptors, leading to an increase in LDL-C removal from the blood. Additionally, studies have shown that in response to statin treatment, there is a compensatory increase in intestinal cholesterol absorption, possibly through the induction of gene expression of such proteins such as NPC1L1. ${ }^{26,43}$ As a corollary, increases in intestinal absorption can lead to downregulation of intrinsic hepatic cholesterol production. ${ }^{42,44}$

Ezetimibe, or 1-(4-fluorophenyl)-(3R)-[3-\{4-fluorophenyl\}$\{3 \mathrm{~S}\}$-hydroxyprophyl]-(4S)-(4-hydroxyphenyl)-(2-azetidinone), inhibits intestinal cholesterol absorption by selectively blocking the NPC1L1 protein in the jejunal brush border, integral to the uptake of intestinal lumen micelles into the enterocyte..$^{24,37,45,46}$ The exact mechanism by which ezetimibe reduces the entry of cholesterol into both enterocytes and hepatocytes is not completely understood. Ge et al suggest ezetimibe prevents the NPC1L1/sterol complex from interacting with AP2 in clathrin coated vesicles. Ezetimibe may change the shape of NPC1L1 so as to render it incapable of binding to sterols or may interfere with the binding of free cholesterol to the cell membrane. ${ }^{41}$ Other hypotheses have been proposed. 
Kramer et al described a $145-\mathrm{kDa}$ integral membrane-bound ectoenzyme called aminopeptidase $\mathrm{N}$ ([alanyl]-aminopeptidase) to which ezetimibe binds. ${ }^{47}$ Annexins are a family of calciumand phospholipid-binding proteins that mediate cholesterol uptake. Caveolin-1 (CAV1) is a small 22-kDa protein that forms at least two distinct chaperone complexes that regulate both total cellular and caveolar cholesterol levels. A complex consisting of annexin 2, cyclophilin A, and cyclophilin 40, traffics exogenous cholesterol from caveolae to the endoplasmic reticulum. The other CAV1 complex includes heat-shock protein 56, cyclophilin A, and cyclophilin 40, and traffics newly synthesized cholesterol from the endoplasmic reticulum to caveolae. It has been shown that ezetimibe effectively disrupts the CAV1annexin 2 heterocomplex in vivo and thereby reduces sterol absorption. ${ }^{48}$ By reducing enterocyte cholesterol absorption, chylomicron formation and secretion, as well as the back flux of cholesterol from the bile, ezetimibe depletes hepatic pools of cholesterol and increases expression of the LDL receptor on the surface of hepatocytes, resulting in reductions in serum levels of LDL-C. ${ }^{49}$ Ezetimibe does not appear to affect the absorption of dietary triglycerides, fat-soluble vitamins, or drugs such as warfarin. After being metabolized through glucoronidation in the small intestine and liver, ezetimibe is excreted in the bile back into the intestinal lumen, where it again can inhibit the NPC1L1 protein..$^{50,51}$ It is eventually excreted predominantly in the feces, with a minor $10 \%$ excretion in the urine. This enterohepatic circuit allows ezetimibe to have a long halflife of 22 hours. Ezetimibe does not undergo metabolism via the cytochrome P450 pathway, and therefore does not have significant interactions with other medications that are metabolized by the cytochrome $\mathrm{P} 450$ pathway, such as statins, fibrates, amiodarone, and amlodipine. ${ }^{52}$ Medications such as fibrates and cyclosporine, though, have been shown to increase the bioavailability of ezetimibe. In addition to inhibition of intestinal cholesterol absorption, ezetimibe also interacts with hepatic NPC1L1, whereby it may reduce biliary cholesterol absorption and further reduce serum cholesterol levels. ${ }^{53}$

A number of preclinical animal studies have shown a consistent reduction in LDL-C levels and vascular benefit with treatment with ezetimibe. ${ }^{54-57}$ Studies using animals fed cholesterol-rich diets showed that ezetimibe effectively lowered serum cholesterol levels. ${ }^{54}$ In ApoE double-knockout mice characterized by severely elevated cholesterol levels and early development of atherosclerosis, ezetimibe at a dosing of $10 \mathrm{mg} / \mathrm{kg}$ per day inhibited cholesterol intestinal absorption by greater than $90 \%$, with significantly reduced levels of chylomicron and VLDL by $87 \% .{ }^{55}$ A synergistic effect of cholesterol lowering was found in dogs treated with a combination of ezetimibe and statin. ${ }^{57}$ In addition to the antilipidemic effects, ezetimibe has been shown to inhibit the progression of aortic and carotid atherosclerosis in ApoE knockout mice treated with varying diets. ${ }^{56}$

Ezetimibe appears to have reported marked variability in intestinal cholesterol absorption and serum cholesterol levels. ${ }^{58}$ Genomic studies have identified over 140 polymorphisms in the NPC1L1 gene and shown that common variants in this gene are associated with differing treatment responses. ${ }^{59,60}$ For example, one identified gene variant, single-nucleotide polymorphism g. $-18 \mathrm{C}>\mathrm{A}$, was associated with a $15 \%$ further reduction in LDL-C as compared to the most common allele after 6 weeks of ezetimibe added on to a background of statin treatment. ${ }^{59}$

Statin therapy significant lowers LDL-C cholesterol levels by $35 \%-60 \%{ }^{4,26}$ While inhibition of hepatic cholesterol production by statins results in a compensatory increase in the production of hepatic LDL receptors and enhanced uptake of serum LDL-C into the liver, there is also an increase in intestinal cholesterol absorption. ${ }^{26}$ Likewise, in animal models, treatment with ezetimibe as monotherapy has been shown to induce $\mathrm{HMG}-\mathrm{CoA}$ reductase expression. ${ }^{24}$ Given these compensatory effects, the adjunctive treatment of hypercholesterolemia using inhibitors of cholesterol absorption such as ezetimibe with statins yields an additive effect on lowering serum cholesterol levels. ${ }^{61}$

\section{Efficacy and indications}

Ezetimibe is indicated in the treatment of disorders of elevated cholesterol levels, including LDL-C and ApoB, as monotherapy or in combination with statins. ${ }^{22}$ The effectiveness of ezetimibe to lower cholesterol and positively change lipid profiles has been noted in a number of clinical trials. ${ }^{17,62-64}$ Given the preponderance of data demonstrating the clinical effectiveness of statin therapy and the current NCEP ATP recommendations for the primary use of statin medications to achieve LDL-C targets, there have only been a small number of clinical trials testing ezetimibe as monotherapy versus placebo. A meta-analysis of eight randomized placebo controlled trials that included over 2700 subjects showed that monotherapy with ezetimibe $10 \mathrm{mg}$ daily in hypercholesterolemic subjects for a minimum of 12 weeks was associated with a significant $18.5 \%$ reduction in LDL-C as compared to placebo. ${ }^{63}$ In addition, there was a significant $3 \%$ increase in HDL-C, a significant $8 \%$ reduction in triglycerides, and a 13\% reduction in total cholesterol with ezetimibe as compared to placebo. Combination therapy trials using ezetimibe plus statin have shown greater efficacy in 
terms of LDL-C reduction than monotherapy with ezetimibe or statin alone. ${ }^{17,65,66}$ A recent meta-analysis was completed of 27 double-blind, placebo-controlled, or active comparative studies of over 21,000 subjects randomized to ezetimibe $10 \mathrm{mg}$ daily plus statin or statin alone for a mean treatment of 9 weeks. ${ }^{66}$ Overall, there was a significant $15.1 \%$ greater observed reduction in LDL-C in the combination therapy with ezetimibe as compared monotherapy with statin. Also, there was a significant $13.5 \%$ greater decrease in non-HDL-C and $8.6 \%$ reduction in high-sensitivity $-\mathrm{C}$-reactive protein. With a greater effect on cholesterol values, the study showed that a higher percentage of subjects were able to reach ATP III treatment targets with the addition of ezetimibe therapy. In subjects with established CHD, only $10.3 \%$ of subjects on statin monotherapy were able to reach an LDL-C goal of $<70 \mathrm{mg} / \mathrm{dL}$, while $32.1 \%$ of subjects on combination therapy with ezetimibe were able to reach this target.

The effectiveness of ezetimibe in lowering cholesterol has been tested in various dyslipidemic populations, including familial hypercholesterolemia (FH). ${ }^{67} \mathrm{FH}$ is an autosomal dominant hereditary disorder caused predominantly by mutations in the LDL-receptor gene resulting in less functional hepatic LDL receptors and subsequent decreased uptake of LDL-C from the blood. ${ }^{68}$ It has a prevalence of 1:500 for heterozygotes and 1:1 million for homozygotes who have almost complete loss of hepatic LDL-receptor activity. FH subjects are often characterized by severely elevated LDL-C, dermatologic findings with xanthomas, and early onset atherosclerotic vascular disease. While statin therapy is the recommended initial treatment of choice along with lifestyle intervention, many FH subjects are frequently unable to reach LDL-C goals even on high-dose statin. ${ }^{69}$ The additive effect of the addition of ezetimibe to statin therapy therefore makes ezetimibe an attractive add-on option for undertreated FH subjects. ${ }^{70}$ In ENHANCE, 720 heterozygous FH subjects were randomized to simvastatin $80 \mathrm{mg}$ daily plus either ezetimibe $10 \mathrm{mg}$ daily or placebo. ${ }^{17}$ After 24 months of treatment, the simvastatin plus ezetimibe group had significantly greater LDL-C reduction as compared to the statin-only group $(-55.6 \%$ vs $-39.1 \% ; P<0.01)$. Given the low prevalence of homozygous FH subjects, there have been only a small number of randomized controlled trial trials testing ezetimibe in this population. One such trial randomized 50 homozygous $\mathrm{FH}$ subjects who were already receiving a background of $40 \mathrm{mg}$ daily of simvastatin or atorvastatin to either increased statin to $80 \mathrm{mg}$ daily, $40 \mathrm{mg}$ daily of statin plus ezetimibe $10 \mathrm{mg}$ daily, or to $80 \mathrm{mg}$ of statin plus ezetimibe $10 \mathrm{mg}$ daily. ${ }^{67}$ After 12 weeks of therapy, there was a greater decrease in LDL-C with addition of ezetimibe to either 40 or $80 \mathrm{mg}$ of statin as compared to doubling of statin to $80 \mathrm{mg}$ from $40 \mathrm{mg}$ daily without the addition of ezetimibe (21\%-27\% vs $7 \%)$.

Ezetimibe can effectively lower sterol levels in subjects with sitosterolemia by inhibiting intestinal plant sterol absorption. ${ }^{71-73}$ An autosomal recessive disorder, sitosterolemia is a condition caused by mutations in the $\mathrm{ABC}$ transporter genes, $A B C G 5$ and $A B C G 8$, which reduce the ability of intestinal cells to transfer free cholesterol back to the intestinal lumen and from the liver into the bile. ${ }^{36}$ This reduction leads to an increase in serum sterol levels of sitosterol and campesterol, and results in the development of early onset atherosclerotic vascular disease. Given the inability of statins to reduce plant sterol levels and the incomplete lowering of sterol levels with other treatments such as low-sterol diets and bile-acid binding resins, ezetimibe has emerged as an effective alternative strategy. ${ }^{72}$ In hypercholesterolemic subjects without a diagnosis of sitosterolemia, ezetimibe therapy for 2 weeks was shown to lower sitosterol and campesterol levels by $41 \%$ and $48 \%$, respectively. ${ }^{74}$ In one small multicenter study, 37 subjects with sitosterolemia were randomized to placebo or ezetimibe $10 \mathrm{mg}$ daily. After 8 weeks of therapy, sterol levels were reduced by $21 \%$ in the ezetimibe group and increased by $4 \%$ in the placebo group. The reduction in sterols with ezetimibe was seen despite subjects concurrently taking bile-acid binders or statins. ${ }^{71}$

Several trials have evaluated the use of ezetimibe in patients with diabetes or metabolic syndrome who often have an atherogenic lipid profile consisting of elevated LDL-C and triglycerides and low HDL-C. ${ }^{75-78}$ The diagnosis of diabetes is considered a CHD-risk equivalent, and current NCEP guidelines recommend a similar LDL-C goal for patients with established CHD or diabetes. ${ }^{12}$ Metabolic syndrome is characterized by a combination of risk factors, including dyslipidemia with elevated triglycerides and low HDL-C, hypertension, obesity based upon waist circumference, and insulin resistance with impaired fasting glucose. ${ }^{79}$ Similar to diabetes, the presence of metabolic syndrome is associated with a high risk of cardiovascular events. In the Vytorin vs Atorvastatin in Patients with Type 2 Diabetes Mellitus and Hypercholesterolemia (VYTAL) trial, 1229 subjects with diabetes and dyslipidemia were randomized to combination therapy with ezetimibe $10 \mathrm{mg}$ /day plus simvastatin $20 \mathrm{mg} /$ day vs atorvastatin $10-20 \mathrm{mg} /$ day or to ezetimibe $10 \mathrm{mg}$ /day plus simvastatin $40 \mathrm{mg}$ /day vs atorvastatin $40 \mathrm{mg} /$ day. ${ }^{76}$ After 6 weeks of therapy, combination therapy with ezetimibe plus simvastatin had greater LDL-C reduction as compared with atorvastatin both 
at the low dose ( $-53.6 \%$ vs $-38.3 \%$, respectively) and the high dose ( $-57.6 \%$ vs $-50.9 \%$, respectively). In addition to a greater ability to lower LDL-C, combination therapy with ezetimibe was better in lowering total cholesterol and non-HDL-C and in raising HDL-C. As compared to the atorvastatin 10-mg dose, ezetimibe 10-mg/simvastatin 20-mg dose was associated with a greater reduction in triglyceride levels. In another study testing an identical protocol as VYTAL in subjects with metabolic syndrome, a similar result was documented with combination therapy, with ezetimibe and simvastatin achieving a greater reduction in LDL-C and non-HDL-C and greater increase in HDL-C as compared to atorvastatin monotherapy. ${ }^{75}$

\section{Safety}

Though side effects have been reported with all lipidaltering therapies such as statins, niacin, and fibrates, lifethreatening toxicities are rare and the overall safety profile of these therapies is quite favorable. ${ }^{80-82}$ The safety of ezetimibe as monotherapy or in combination with other lipid-modifying agents such as statins has been well documented. ${ }^{63,75}$ In terms of elevations in liver function tests, ezetimibe appears to cause similar elevations in transaminases (three times the upper limit of normal with alanine transaminase or aspartate transaminase) as compared to placebo when given as monotherapy. ${ }^{47}$ Also, as combination therapy with statins, ezetimibe does not significantly cause an increase in liver enzymes more than is observed with statin therapy alone. In a meta-analysis of 18 randomized controlled trails evaluating statin plus ezetimibe or placebo in 14,471 subjects, the incidence of elevations in liver enzymes was not statistically different between the two groups. ${ }^{66}$ Life-threatening liver failure with ezetimibe as monotherapy or in combination with statins is extremely rare, with only a handful of published reported cases. ${ }^{83-85}$ Myalgias with or without myositis and elevations in creatinine kinase are commonly reported with treatment with statins. ${ }^{86}$ The addition of ezetimibe to statin therapy does not appear to increase the incidence of elevated creatinine kinase levels beyond what is noted with treatment with statin alone. A meta-analysis of seven randomized controlled trials showed that monotherapy with ezetimibe or in combination with statin was not associated with an increased risk of myositis as compared to placebo or monotherapy with statin. ${ }^{87}$

Several epidemiological trials have raised concerns of an increased risk of cancer associated with low total serum cholesterol levels that have been reproduced in a small number of randomized controlled statin trials..$^{5,88-91}$ The recent publication of the Simvastatin and Ezetimibe in Aortic Stenosis (SEAS) study raised similar concerns for cancer with treatment with ezetimibe plus statin. ${ }^{92}$ In SEAS, 1873 subjects with a history of asymptomatic aortic stenosis were randomized to ezetimibe $10 \mathrm{mg} /$ day and simvastatin $40 \mathrm{mg} /$ day or placebo. There was a higher rate of cancer incidence in the ezetimibe/simvastatin group $(11.1 \%)$ than in the placebo group $(7.5 \%)$. However, a combined analysis of two larger ezetimibe-plus-statin trials that were ongoing at the time of the analysis did not support such a hypothesis. In this interim analysis, incident cancer cases from the Study of Heart and Renal Protection (SHARP) and Improved Reduction of Outcomes: Vytorin Efficacy International Trial (IMPROVE-IT) studies with 20,617 subjects showed no increased risk of cancer with treatment with ezetimibe plus statin as compared to statin alone. ${ }^{93}$ Also, the study showed that there was no increased risk of new cancer diagnosis associated with duration of treatment. Since the publication of this combined analysis, the SHARP trial has been completed and confirmed no difference in cancer rates between the combination therapy and placebo $(9.4 \%$ vs $9.5 \%, P=0.89) .{ }^{65}$ Final cancer-event data is not yet available for the IMPROVE-IT trial, which is ongoing, but no recommendations for early termination of the trial have been reported by the data-monitoring and safety board, which suggests that no significant increase in cancer risk has been detected.

\section{Imaging trials evaluating effects on atherosclerosis}

The vascular effects of ezetimibe on atherosclerosis progression have been investigated in several trials using ultrasound measurements of CIMT. ${ }^{17,94,95}$ Numerous population studies have documented CIMT as a marker for CHD risk. Documenting changes to CIMT has become a common surrogate marker of atherosclerosis progression or regression in evaluating the clinical effectiveness of lipidaltering therapies. ${ }^{96}$ The ENHANCE study investigated the vascular effect as measured by CIMT of combination therapy with simvastatin $80 \mathrm{mg}$ /day plus either ezetimibe $10 \mathrm{mg} /$ day or placebo in subjects with heterozygous $\mathrm{FH} .{ }^{17}$ After 24 months of treatment and despite a significant difference in LDL-C lowering $(-55.6 \%$ vs $-39.1 \%, P<0.01)$ favoring combination therapy with ezetimibe, there was no significant difference in CIMT measurements $(+0.0033 \mathrm{~mm}$ for placebo vs $0.0182 \mathrm{~mm}$ for ezetimibe, $P=0.15$ ). This negative finding was contrary to the prior Atorvastatin Versus Simvastatin on Atherosclerosis Progression (ASAP) trial, which showed that high-dose treatment using atorvastatin $80 \mathrm{mg} /$ day in subjects with heterozygous FH led to a 
greater reduction in LDL-C as compared to treatment with moderate-dose simvastatin of $40 \mathrm{mg} /$ day. ${ }^{97}$ This difference in LDL-C reduction was associated with regression of CIMT of $-0.031 \mathrm{~mm}$ in the atorvastatin group and progression of $+0.036 \mathrm{~mm}$ in the simvastatin group $(P=0.0001$ for between-group comparison). Though ENHANCE failed to produce similar effects on CIMT as seen in ASAP, several fundamental differences exist between the two study populations that may account for the discordant findings. The baseline CIMT seen in ENHANCE $(0.70 \mathrm{~mm})$ was significantly thinner than in ASAP $(0.92 \mathrm{~mm})$. In addition, the change in CIMT over 2 years in the monotherapy groups treated with simvastatin was significantly less in ENHANCE $(0.0058 \mathrm{~mm})$ than ASAP $(0.0360 \mathrm{~mm})$, despite similar effects on LDL-C. These findings in ASAP and ENHANCE suggest that the heterozygous FH subjects in ENHANCE had been previously well treated with chronic statin therapy and may have entered the study with carotid arteries already depleted of lipid and therefore resistant to further changes in response to new lipid therapies. ${ }^{98}$ Support for this hypothesis was provided by data from the Carotid Atorvastatin Study in Hyperlipidemic post-Menopausal Women: A Randomized Evaluation (CASHMERE) trial. CASHMERE randomized 398 postmenopausal women with moderate hypercholesterolemia to treatment with atorvastatin $80 \mathrm{mg}$ daily, hormone replacement therapy alone, combination, or placebo and measured change in CIMT as a vascular outcome. ${ }^{99} \mathrm{After} 12$ months of therapy, there was no reported change in CIMT despite greater LDL-C reduction on high-dose atorvastatin as compared to placebo. The mean baseline CIMT was $0.69 \mathrm{~mm}$, which was similar to that of ENHANCE. This low baseline CIMT measurement observed in both trials likely limited the measurable incremental change to carotid atherosclerosis in response to additional lipid-lowering therapy.

A positive impact on carotid atherosclerosis using ezetimibe was observed in the Stop Atherosclerosis in Native Diabetics Study (SANDS). ${ }^{94,100}$ SANDS randomized diabetic subjects to aggressive care with target LDL-C $<70 \mathrm{mg} / \mathrm{dL}$ and systolic blood pressure $<115 \mathrm{mmHg}$ or to standard care with target LDL-C $<100 \mathrm{mg} / \mathrm{dL}$ and systolic blood pressure $<130 \mathrm{mmHg}$. Ezetimibe was added on to statin therapy in subjects not able to meet LDL-C targets. Change in carotid IMT was compared between the aggressive versus standard treatment groups and between subjects receiving statins plus ezetimibe versus statins alone. After 36 months of therapy, LDL-C was reduced similarly in the aggressive treatment group receiving statins plus ezetimibe $(-31 \mathrm{mg} / \mathrm{dL})$ or statins alone $(-32 \mathrm{mg} / \mathrm{dL})$. Mean baseline CIMT in SANDS was $0.81 \mathrm{~mm}$ as compared to $0.69 \mathrm{~mm}$ seen in ENHANCE. In the standard therapy group, there was progression of CIMT by $+0.039 \mathrm{~mm}$, while the aggressively treated group showed CIMT regression from baseline in both the ezetimibe $(-0.025 \mathrm{~mm})$ and nonezetimibe $(-0.012 \mathrm{~mm})$ subjects. In multivariate analysis, change in CIMT was related to degree of LDL-C reduction independent of specific choice of lipidlowering therapy.

Further support for the vascular benefits of combination therapy with ezetimibe was reported in the Vytorin on Carotid Intima-Media Thickness and Overall Arterial Rigidity (VYCTOR) study, which randomized 90 coronary artery disease subjects to pravastatin $40 \mathrm{mg} /$ day \pm ezetimibe $10 \mathrm{mg} /$ day, simvastatin $40-80 \mathrm{mg} /$ day, or simvastatin $20-40 \mathrm{mg} /$ day \pm ezetimibe $10 \mathrm{mg} /$ day with a primary end point of change in CMIT. ${ }^{101}$ After 1 year of therapy, there was significant reduction in LDL-C to a mean level of $45-48 \mathrm{mg} / \mathrm{dL}$ in the three groups. Baseline CIMT was $1.23-1.33 \mathrm{~mm}$, almost twice that of the baseline in ENHANCE. Follow-up measurement of CIMT showed a significant reduction in all three groups to a level of $0.90-0.93 \mathrm{~mm}$. The results of SANDS and VYCTOR are contradictory to the outcome observed in ENHANCE and suggest that treatment with ezetimibe can regress carotid atherosclerosis if there is a sufficiently thick CIMT at baseline.

Despite the positive results of the SANDS and VYCTOR trials, additional questions were raised regarding the vascular benefits of ezetimibe following the early termination of the Arterial Biology for the Investigation of the Treatment Effects of Reducing Cholesterol 6-HDL and LDL Treatment Strategies (ARBITER 6 - HALTS) study. ${ }^{102,103}$ ARBITER 6 randomized 363 coronary artery disease subjects with CHD or CHD equivalent, treated LDL-C $<100 \mathrm{mg} / \mathrm{dL}$ on background statin therapy and low HDL-C to treatment with ezetimibe $10 \mathrm{mg} /$ day or extended-release niacin target to $2000 \mathrm{mg} /$ day. ${ }^{95}$ The primary end point of the study was change in mean CIMT. The study was stopped early after 14 months of follow-up after reaching a prespecified efficacy end point. Changes to lipid profiles were as expected with treatment, with niacin raising HDL-C by $18.4 \%$ to $50 \mathrm{mg} / \mathrm{dL}$ and ezetimibe lowering LDL-C by $19.2 \%$ to $66 \mathrm{mg} / \mathrm{dL}$. A significant reduction in CIMT $(-0.0142 \mathrm{~mm}, P=0.001)$ in the niacin group was reported, while a nonsignificant reduction $(-0.0007 \mathrm{~mm}, P=0.84)$ was noted in the ezetimibe group. The authors concluded based upon these results that treatment with niacin in combination with statin was superior to ezetimibe on regression of CIMT. 
These results are consistent with prior data documenting niacin's ability to stabilize or regress atherosclerosis and lend support to the use of niacin in the treatment of low HDL-C. However, several issues exist in trying to extrapolate these findings to conclude on the effectiveness of ezetimibe on carotid atherosclerosis. First, ARBITER-6 was designed to evaluate the treatment of subjects with low HDL-C and controlled LDL-C. Such a population was ideally suited for therapy with niacin and not with ezetimibe which is used primarily to reduce LDL-C. While niacin treatment raised HDL-C by $7.5 \mathrm{mg} /$ $\mathrm{dL}$, therapy with ezetimibe lowered HDL-C by $2.8 \mathrm{mg} / \mathrm{dL}$. Additionally, as noted in prior carotid imaging trials including ASAP and ENHANCE, changes in carotid atherosclerosis occur in the first 1-2 years after initiating LDL-C-lowering therapy and are not expected in subjects who have been on chronic lipid-lowering treatment. ARBITER 6 subjects were on a background of aggressive statin therapy for an average of 6 years prior to study enrollment, which could have impacted their capacity for additional LDL-C reduction with ezetimibe to reduce CIMT. Also, the trial was stopped prematurely, with over $40 \%$ of the subjects not having undergone follow-up CIMT measurements, and this could have minimized any possible vascular effects due to ezetimibe. Based on these methodological study design flaws, definitive conclusions on the presence or absence of vascular benefit of ezetimibe cannot be made using data presented in ARBITER-6.

\section{Clinical outcome trials}

The clinical efficacy of ezetimibe treatment was evaluated in the SEAS study, where 1873 subjects with mild to moderate aortic stenosis without indication for lipid-lowering therapy were randomized to ezetimibe $10 \mathrm{mg}$ /day plus simvastatin $40 \mathrm{mg}$ /day or placebo..$^{2}$ The primary end point was a composite of need for aortic valve surgery and cardiovascular events. After 4 years of therapy, combination therapy with ezetimibe reduced LDL-C by $61 \%$ as compared to placebo. While there was no significant difference in the primary end point, major cardiovascular events with fatal and nonfatal myocardial infarction were significantly reduced by $41 \%$ in the simvastatin plus ezetimibe group (Figure 3 ). This cardiovascular event reduction was proportional to the magnitude of LDL-C change and was only apparent in subjects with less severe aortic stenosis, defined as tertiles 1 and 2 as based upon aortic jet velocity. ${ }^{104}$ This degree of event reduction based upon the level of LDL-C reduction was similar to what was previously observed in a meta-analysis of 14 statin trials showing the benefit of statin therapy versus placebo completed by the Cholesterol Treatment Trialists' Collaboration. ${ }^{80}$
Similar evidence supportive of a cardiovascular benefit in using statin plus ezetimibe treatment was noted in the SHARP trial. ${ }^{65}$ In SHARP, subjects with chronic kidney disease with and without dialysis dependence were randomized to simvastatin $20 \mathrm{mg}$ /day plus ezetimibe $10 \mathrm{mg}$ /day or placebo. After 5 years of therapy, there was a significant $17 \%$ reduction in major atherosclerotic events in the ezetimibe groups as compared to placebo $(P=0.0021)$. Risk reduction was again found to be proportional to magnitude of LDL-C reduction. No increased risk of adverse events was reported, including myopathy and rhabdomyolysis. This positive outcome was in contrast to two previously reported negative trials evaluating lipid-lowering with statins in renal disease subjects; A Study to Evaluate the Use of Rosuvastatin in Subjects on Regular Hemodialysis: An Assessment of Survival and Cardiovascular Events (AURORA) and German Diabetes and Dialysis Study (4D). ${ }^{105,106}$ In addition to the fact that SHARP was a significantly larger trial with three times greater enrollment than AURORA and 4D combined, the likely main explanation for the discrepant findings was that the SHARP population had less advanced kidney disease. While AURORA and 4D evaluated lipid therapy in subjects who were already undergoing hemodialysis, the SHARP trial only had a third of its population being dialysis-dependent. Lipid therapy would be expected to benefit less advanced kidney disease subjects, who predominantly succumb to deaths related to atherosclerotic-based heart disease, but not in dialysis-dependent subjects, who experience more arrhythmiarelated deaths. ${ }^{107}$

Despite the atherosclerosis regression documented in SANDS and VYCTOR and cardiovascular benefit seen in SEAS and SHARP using combination therapy with ezetimibe, the negative outcomes reported from ENHANCE and ARBITER 6 produced significant controversy on the clinical value of ezetimibe in the treatment of hypercholesterolemia. ${ }^{23,98,102}$ Also, to date, no randomized trial has shown a significant reduction in clinical events with combination therapy using ezetimibe plus statin versus statin alone. Therefore, the results from the soon-to-becompleted IMPROVE-IT are highly anticipated. ${ }^{108}$ The goal of IMPROVE-IT is to evaluate the effect of additional LDL-C lowering using ezetimibe on top of intensive background statin therapy on cardiovascular events in 18,000 subjects who have had recent acute coronary syndromes. But while the trial is not expected to be completed until June 2013, questions already exist about the ability of the trial to detect incremental benefit of ezetimibe added on to statin therapy. Subjects in IMPROVE-IT were treated at baseline with optimal medical therapy post-acute coronary syndrome and 


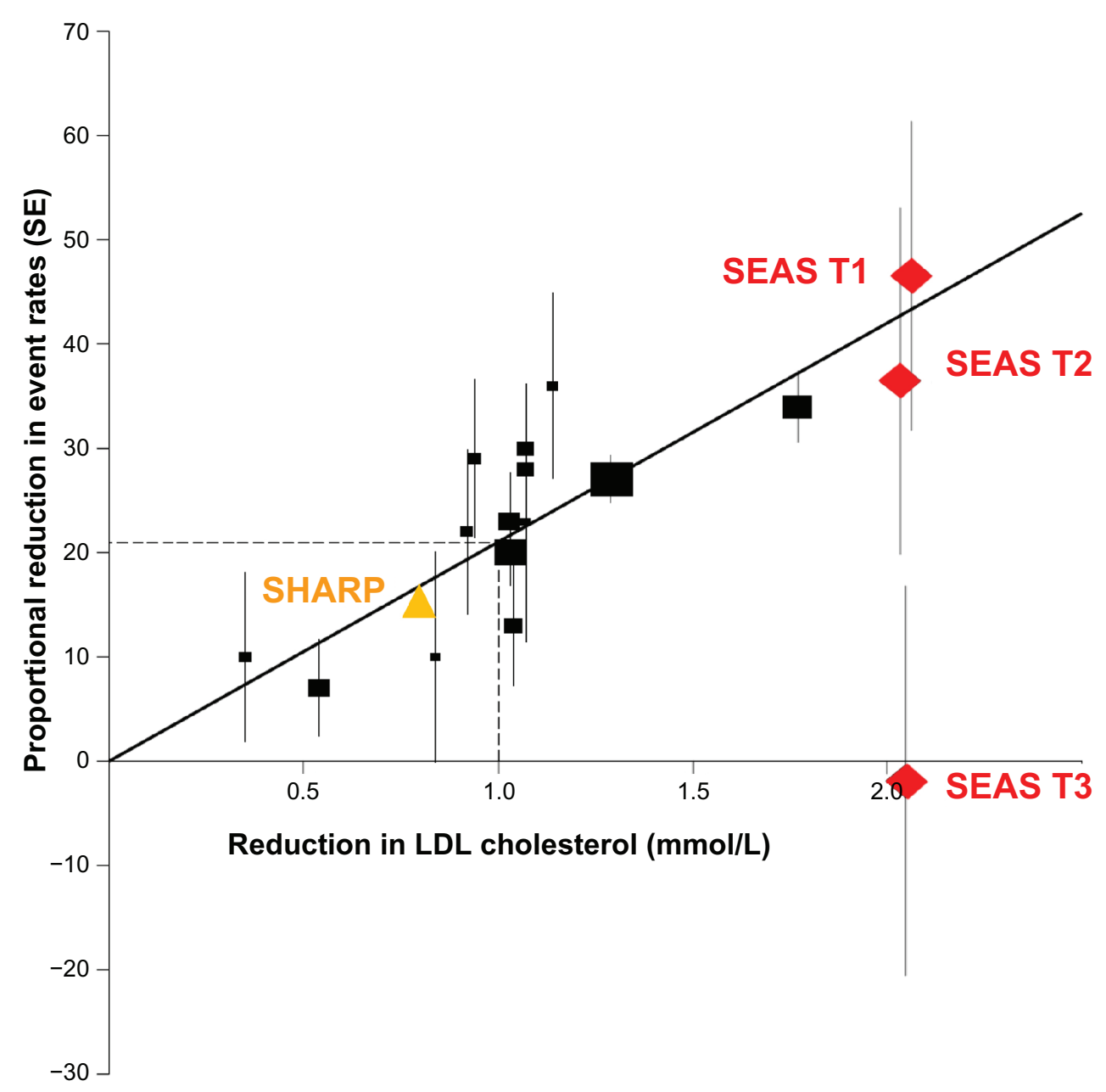

Figure 3 Proportional reduction in major ischemic events by mean decrease in LDL-C (mmol/L) in the Simvastatin and Ezetimibe in Aortic Stenosis (SEAS) trial (tertiles I, 2, and 3 for severity of aortic valve stenosis) compared to 14 randomized trials in the Cholesterol Treatment Trialists meta-analysis.

Copyright (C) 20I0, Elsevier. Adapted with permission from Holme I, Boman K, Brudi P, et al. Observed and predicted reduction of ischemic cardiovascular events in the Simvastatin and Ezetimibe in Aortic Stenosis Trial. Am J Cardiol. 2010;105:1802-1808. ${ }^{104}$ The Study of Heart and Renal Protection (SHARP) data point is based on Baigent et al. ${ }^{65} \mathrm{I} \mathrm{mmol} / \mathrm{L}$ approximates to $39 \mathrm{mg} / \mathrm{dL}$ of LDL-C.

Abbreviation: LDL-C, low-density lipoprotein cholesterol.

were thought to be able to reach aggressive LDL-C targets based upon NCEP ATP III updated recommendations with treatment with simvastatin $40 \mathrm{mg} /$ day plus placebo (the trial will be comparing mean attained LDL-C levels of $66 \mathrm{mg} / \mathrm{dL}$ and $52 \mathrm{mg} / \mathrm{dL}$ ). ${ }^{109}$ Given the already low LDL-C levels and reduced cardiovascular events with simvastatin-only therapy in this population, the further reduction of cardiovascular events with the addition of ezetimibe will likely be of modest value. Beyond the large sample size, IMPROVE-IT will need an adequate number of events to provide enough power to detect the expected small difference between the ezetimibe and placebo groups. Ideally, a trial comparing ezetimibe monotherapy versus placebo in hypercholesterolemic subjects would provide the best answer on ezetimibe's ability to lower LDL-C and subsequently affect cardiovascular events. But unfortunately, given the long-established benefit of statin therapy, a cholesterol trial without statin therapy would not be possible today, particularly in subjects with CHD.

\section{Conclusion}

In the current treatment of cardiovascular disease, many subjects fail to reach LDL-C targets or remain at high risk for CHD events despite optimal statin and medical therapy. Ezetimibe inhibits intestinal cholesterol absorption and is effective in lowering cholesterol as monotherapy or in combination with statins in several populations, including those with $\mathrm{FH}$, sitosterolemia, and insulin resistance. Significant controversy has been generated regarding the clinical effectiveness of ezetimibe, particularly after the publication of ENHANCE and ARBITER-6 despite both trials having significant methodological flaws that limited their ability to evaluate the benefit of ezetimibe. Growing data suggest that ezetimibe in 
combination with statin has a positive effect on the progression of atherosclerosis and reduces cardiovascular events in subjects at risk for CHD, including those with chronic kidney disease. Results from IMPROVE-IT are forthcoming and may help to guide better the use of ezetimibe in very high-risk CHD populations. Until that time and based upon the current available data, ezetimibe should remain a viable adjunct to statin therapy in the treatment of hypercholesterolemia.

\section{Disclosure}

Binh An Phan is a speaker for Abbott. Thomas Dayspring consults for Abbott, GSK, Health Diagnostic Labs, Kowa Company, Eli Lilly, Merck, Genentech, The Roche Group, Genzyme, and Omthera. He is on the Lecture Bureau for Abbott, GSK, Health Diagnostic Labs, Kowa, Eli Lilly, LipoScience, Merck. Peter P Toth is a speaker for Abbott, AstraZeneca, Amylin, Boehringer-Ingelheim, GSK, Kowa, Merck and consults for Abbott, Aegerion, AstraZeneca, Atherotech, Genzyme, Genentech, Kowa, and Merck.

\section{References}

1. Kannel WB, Castelli WP, Gordon T. Cholesterol in the prediction of atherosclerotic disease. An Intern Med. 1979;90:85-91.

2. Keys A, Menotti A, Aravanis C, et al. The seven countries study: 2,289 deaths in 15 years. Prev Med. 1984;13:141-154.

3. Heart Protection Study Collaborative Group. MRC/BHF Heart Protection Study of cholesterol lowering with simvastatin in 20,536 high-risk individuals: a randomised placebo-controlled trial. Lancet. 2002;360:7-22.

4. [No authors listed]. Randomised trial of cholesterol lowering in 4444 patients with coronary heart disease: the Scandinavian Simvastatin Survival Study (4S). Lancet. 1994;344:1383-1389.

5. Sacks FM, Pfeffer MA, Moye LA, et al. The effect of pravastatin on coronary events after myocardial infarction in patients with average cholesterol levels. Cholesterol and Recurrent Events Trial investigators. N Engl J Med. 1996;335:1001-1009.

6. Shepherd J, Cobbe SM, Ford I, et al. Prevention of coronary heart disease with pravastatin in men with hypercholesterolemia. West of Scotland Coronary Prevention Study Group. N Engl J Med. 1995;333: 1301-1307.

7. Downs JR, Clearfield M, Weis S, et al. Primary prevention of acute coronary events with lovastatin in men and women with average cholesterol levels: results of AFCAPS/TexCAPS. JAMA. 1998;279: 1615-1622.

8. National Cholesterol Education Program (NCEP) Expert Panel on Detection, Evaluation, and Treatment of High Blood Cholesterol in Adults (Adult Treatment Panel III). Third Report of the National Cholesterol Education Program (NCEP) Expert Panel on Detection, Evaluation, and Treatment of High Blood Cholesterol in Adults (Adult Treatment Panel III) final report. Circulation. 2002;106: 3143-3421.

9. LaRosa JC, Grundy SM, Waters DD, et al. Intensive lipid lowering with atorvastatin in patients with stable coronary disease. $N$ Engl $\mathrm{J} \mathrm{Med}$. 2005;352:1425-1435.

10. Cannon $\mathrm{CP}$, Braunwald $\mathrm{E}, \mathrm{McCabe} \mathrm{CH}$, et al. Intensive versus moderate lipid lowering with statins after acute coronary syndromes. $N$ Engl $J$ Med. 2004;350:1495-1504.

11. Cannon CP, Steinberg BA, Murphy SA, Mega JL Braunwald E. Metaanalysis of cardiovascular outcomes trials comparing intensive versus moderate statin therapy. J Am Coll Cardiol. 2006;48:438-445.
12. Grundy SM, Cleeman JI, Merz CN, et al. Implications of recent clinical trials for the National Cholesterol Education Program Adult Treatment Panel III Guidelines. J Am Coll Cardiol. 2004;44:720-732.

13. Catapano AL. Perspectives on low-density lipoprotein cholesterol goal achievement. Curr Med Res Opin. 2009;25:431-447.

14. Pearson TA, Laurora I, Chu H, Kafonek S. The lipid treatment assessment project (L-TAP): a multicenter survey to evaluate the percentages of dyslipidemic patients receiving lipid-lowering therapy and achieving low-density lipoprotein cholesterol goals. Arch Intern Med. 2000;160:459-467.

15. Waters DD, Brotons C, Chiang CW, et al. Lipid treatment assessment project 2: a multinational survey to evaluate the proportion of patients achieving low-density lipoprotein cholesterol goals. Circulation. 2009; 120:28-34.

16. Taylor AJ, Sullenberger LE, Lee HJ, Lee JK, Grace KA. Arterial Biology for the Investigation of the Treatment Effects of Reducing Cholesterol (ARBITER) 2: a double-blind, placebo-controlled study of extendedrelease niacin on atherosclerosis progression in secondary prevention patients treated with statins. Circulation. 2004;110:3512-3517.

17. Kastelein JJP, Akdim F, Stroes ESG, et al. Simvastatin with or without ezetimibe in familial hypercholesterolemia. New Engl J Med. 2008;358: 1431-1443.

18. Brown BG, Zhao XQ, Chait A, et al. Simvastatin and niacin, antioxidant vitamins, or the combination for the prevention of coronary disease. N Engl J Med. 2001;345:1583-1592.

19. Brown G, Albers JJ, Fisher LD, et al. Regression of coronary artery disease as a result of intensive lipid-lowering therapy in men with high levels of apolipoprotein B. N Engl J Med. 1990;323:1289-1298.

20. Buchwald H, Varco RL, Matts JP, et al. Effect of partial ileal bypass surgery on mortality and morbidity from coronary heart disease in patients with hypercholesterolemia. Report of the Program on the Surgical Control of the Hyperlipidemias (POSCH). N Engl J Med. 1990;323:946-955.

21. Robinson JG, Wang S, Smith BJ, Jacobson TA. Meta-analysis of the relationship between non-high-density lipoprotein cholesterol reduction and coronary heart disease risk. J Am Coll Cardiol. 2009;53: 316-322.

22. Toth PP, Davidson MH. Cholesterol absorption blockade with ezetimibe. Curr Drug Targets Cardiovasc Haematol Disord. 2005;5: 455-462.

23. Brown BG, Taylor AJ. Does ENHANCE diminish confidence in lowering LDL or in ezetimibe? New Engl J Med. 2008;358:1504-1507.

24. Bays H. Ezetimibe. Expert Opin Investig Drugs. 2002;11:1587-1604.

25. Burnett JR, Huff MW. Cholesterol absorption inhibitors as a therapeutic option for hypercholesterolaemia. Expert Opin Investig Drugs. 2006;15: 1337-1351.

26. Huff MW, Burnett JR. 3-Hydroxy-3-methylglutaryl coenzyme A reductase inhibitors and hepatic apolipoprotein B secretion. Curr Opin Lipidol. 1997;8:138-145.

27. Ikonen E. Mechanisms for cellular cholesterol transport: defects and human disease. Physiol Rev. 2006;86:1237-1261.

28. Dietschy JM, Turley SD, Spady DK. Role of liver in the maintenance of cholesterol and low density lipoprotein homeostasis in different animal species, including humans. J Lipid Res. 1993;34:1637-1659.

29. Lewis GF, Rader DJ. New insights into the regulation of HDL metabolism and reverse cholesterol transport. Circ Res. 2005;96: 1221-1232.

30. Barter P, Rye KA. Cholesteryl ester transfer protein: its role in plasma lipid transport. Clin Exp Pharmacol Physiol. 1994;21:663-672.

31. Kruit JK, Groen AK, van Berkel TJ, Kuipers F. Emerging roles of the intestine in control of cholesterol metabolism. World J Gastroenterol. 2006;12:6429-6439.

32. Davis HR Jr, Basso F, Hoos LM, Tetzloff G, Lally SM, Altmann SW. Cholesterol homeostasis by the intestine: lessons from Niemann-Pick C1 Like 1 [NPC1L1). Atheroscler Suppl. 2008;9:77-81.

33. Iqbal J, Hussain MM. Intestinal lipid absorption. Am J Physiol Endocrinol Metab. 2009;296:E1183-E1194. 
34. Yu L, Li-Hawkins J, Hammer RE, et al. Overexpression of ABCG5 and ABCG8 promotes biliary cholesterol secretion and reduces fractional absorption of dietary cholesterol. J Clin Invest. 2002;110: 671-680.

35. Lee MH, Lu K, Patel SB. Genetic basis of sitosterolemia. Curr Opin Lipidol. 2001;12:141-149.

36. Salen G, Patel S, BattaAK. Sitosterolemia. Cardiovasc Drug Rev. 2002;20: 255-270.

37. Altmann SW, Davis HR Jr, Zhu LJ, et al. Niemann-Pick C1 Like 1 protein is critical for intestinal cholesterol absorption. Science. 2004;303: 1201-1204.

38. Radhakrishnan A, Sun LP, Kwon HJ, Brown MS, Goldstein JL. Direct binding of cholesterol to the purified membrane region of SCAP: mechanism for a sterol-sensing domain. Mol Cell. 2004;15: 259-268.

39. Weinglass AB, Kohler M, Schulte U, et al. Extracellular loop C of NPC1L1 is important for binding to ezetimibe. Proc Natl Acad Sci U S A. 2008;105:11140-11145.

40. Pearse BM, Smith CJ, Owen DJ. Clathrin coat construction in endocytosis. Curr Opin Struct Biol. 2000;10:220-228.

41. Ge L, Wang J, Qi W, et al. The cholesterol absorption inhibitor ezetimibe acts by blocking the sterol-induced internalization of NPC1L1. Cell Metab. 2008;7:508-519.

42. Santosa S, Varady KA, AbuMweis S, Jones PJH. Physiological and therapeutic factors affecting cholesterol metabolism: does a reciprocal relationship between cholesterol absorption and synthesis really exist? Life Sci. 2007;80:505-514.

43. Bays H, Stein EA. Pharmacotherapy for dyslipidaemia - current therapies and future agents. Expert Opin Pharmacother. 2003;4:1901-1938.

44. Catapano AL. The pharmacologic elegance of inhibiting cholesterol absorption and synthesis while providing a homeostatic balance. Fundam Clin Pharmacol. 2007;21 Suppl 2:21-26.

45. Rosenblum SB, Huynh T, Afonso A, et al. Discovery of 1-(4fluorophenyl)-(3R)-[3-(4-fluorophenyl)-(3S)-hydroxypropyl]-(4S)(4-hydroxyphenyl)-2-azetidinone ( $\mathrm{SCH} 58235$ ): a designed, potent, orally active inhibitor of cholesterol absorption. J Med Chem. 1998;41: 973-980.

46. Davis HR Jr, Tershakovec AM, Tomassini JE, Musliner T. Intestinal sterol transporters and cholesterol absorption inhibition. Curr Opin Lipidol. 2011;22:467-478.

47. Kramer W, Girbig F, Corsiero D, et al. Aminopeptidase N (CD13) is a molecular target of the cholesterol absorption inhibitor ezetimibe in the enterocyte brush border membrane. J Biol Chem. 2005;280: $1306-1320$.

48. Smart EJ, De Rose RA, Farber SA. Annexin 2-caveolin 1 complex is a target of ezetimibe and regulates intestinal cholesterol transport. Proc Natl Acad Sci U S A. 2004;101:3450-3455.

49. Temel RE, Tang W, Ma Y, et al. Hepatic Niemann-Pick C1-like 1 regulates biliary cholesterol concentration and is a target of ezetimibe. J Clin Invest. 2007;117:1968-1978.

50. Ghosal A, Hapangama N, Yuan Y, et al. Identification of human UDPglucuronosyltransferase enzyme(s) responsible for the glucuronidation of ezetimibe (Zetia). Drug Metab Dispos. 2004;32:314-320.

51. van Heek M, Farley C, Compton DS, et al. Comparison of the activity and disposition of the novel cholesterol absorption inhibitor, SCH58235, and its glucuronide, SCH60663. Br J Pharmacol. 2000;129: $1748-1754$.

52. Jeu L, Cheng JWM. Pharmacology and therapeutics of ezetimibe (SCH 58235), a cholesterol-absorption inhibitor. Clin Ther. 2003;25: 2352-2387.

53. Garcia-Calvo M, Lisnock J, Bull HG, et al. The target of ezetimibe is Niemann-Pick C1-Like 1 (NPC1L1). Proc Natl Acad Sci U SA. 2005;102: 8132-8137.

54. van Heek M, Compton DS, Davis HR. The cholesterol absorption inhibitor, ezetimibe, decreases diet-induced hypercholesterolemia in monkeys. Eur J Pharmacol. 2001;415:79-84.
55. Repa JJ, Turley SD, Quan G, Dietschy JM. Delineation of molecular changes in intrahepatic cholesterol metabolism resulting from diminished cholesterol absorption. J Lipid Res. 2005;46:779-789.

56. Dietrich T, Hucko T, Bourayou R, et al. High resolution magnetic resonance imaging in atherosclerotic mice treated with ezetimibe. Int $J$ Cardiovasc Imaging. 2009;25:827-836.

57. Davis HR Jr, Pula KK, Alton KB, Burrier RE, Watkins RW. The synergistic hypocholesterolemic activity of the potent cholesterol absorption inhibitor, ezetimibe, in combination with 3-hydroxy-3methylglutaryl coenzyme a reductase inhibitors in dogs. Metab Clin Exp. 2001;50:1234-1241.

58. Lioudaki E, Ganotakis ES, Mikhailidis DP. Ezetimibe; more than a low density lipoprotein cholesterol lowering drug? An update after 4 years. Curr Vasc Pharmacol. 2011;9:62-86.

59. Simon JS, Karnoub MC, Devlin DJ, et al. Sequence variation in NPC1L1 and association with improved LDL-cholesterol lowering in response to ezetimibe treatment. Genomics. 2005;86:648-656.

60. Cohen JC, Pertsemlidis A, Fahmi S, et al. Multiple rare variants in NPC1L1 associated with reduced sterol absorption and plasma low-density lipoprotein levels. Proc Natl Acad Sci U S A. 2006;103: 1810-1815.

61. Guyton JR. Combination regimens with statin, niacin, and intestinally active LDL-lowering drugs: alternatives to high-dose statin therapy? Curr Opin Lipidol. 2010;21:372-377.

62. Gazi IF, Daskalopoulou SS, Nair DR, Mikhailidis DP. Effect of ezetimibe in patients who cannot tolerate statins or cannot get to the low density lipoprotein cholesterol target despite taking a statin. Curr Med Res Opin. 2007;23(9):2183-2192.

63. Pandor A, Ara RM, Tumur I, et al. Ezetimibe monotherapy for cholesterol lowering in 2,722 people: systematic review and meta-analysis of randomized controlled trials. J Intern Med. 2009;265:568-580.

64. Gagné C, Bays HE, Weiss SR, et al. Efficacy and safety of ezetimibe added to ongoing statin therapy for treatment of patients with primary hypercholesterolemia. Am J Cardiol. 2002;90:1084-1091.

65. Baigent C, Landray MJ, Reith C, et al. The effects of lowering LDL cholesterol with simvastatin plus ezetimibe in patients with chronic kidney disease (Study of Heart and Renal Protection): a randomised placebo-controlled trial. Lancet. 2011;377:2181-2192.

66. Morrone D, Weintraub WS, Toth PP, et al. Lipid-altering efficacy of ezetimibe plus statin and statin monotherapy and identification of factors associated with treatment response: A pooled analysis of over 21,000 subjects from 27 clinical trials. Atherosclerosis. Epub February 16, 2012.

67. Hamilton-Craig I, Kostner K, Colquhoun D, Woodhouse S. Combination therapy of statin and ezetimibe for the treatment of familial hypercholesterolemia. Vasc Health Risk Manag. 2010;6:1023-1037.

68. Soutar AK, Naoumova RP. Mechanisms of disease: genetic causes of familial hypercholesterolemia. Nat Clin Pract Cardiovasc Med. 2007;4:214-225.

69. Naoumova RP, Thompson GR, Soutar AK. Current management of severe homozygous hypercholesterolaemias. Curr Opin Lipidol. 2004;15: 413-422.

70. Pitsavos C, Skoumas I, Tousoulis D, et al. The impact of ezetimibe and high-dose of statin treatment on LDL levels in patients with heterozygous familial hypercholesterolemia. Int J Cardiol. 2009;134:280-281.

71. Salen G, von Bergmann K, Lütjohann D, et al. Ezetimibe effectively reduces plasma plant sterols in patients with sitosterolemia. Circulation. 2004;109:966-971.

72. Tsubakio-Yamamoto K, Nishida M, Nakagawa-Toyama Y, Masuda D, Ohama T, Yamashita S. Current therapy for patients with sitosterolemiaeffect of ezetimibe on plant sterol metabolism. J Atheroscler Thromb. 2010;17:891-900.

73. Lütjohann D, von Bergmann K, Sirah W, et al. Long-term efficacy and safety of ezetimibe $10 \mathrm{mg}$ in patients with homozygous sitosterolemia: a 2-year, open-label extension study. Int J Clin Pract. 2008;62: $1499-1510$ 
74. Sudhop T, Lütjohann D, Reber D. Inhibition of intestinal cholesterol absorption and endogenous cholesterol synthesis by ezetimibe/ simvastatin in humans. J Am Coll Cardiol 2005;45:392A.

75. Robinson JG, Ballantyne CM, Grundy SM, et al. Lipid-altering efficacy and safety of ezetimibe/simvastatin versus atorvastatin in patients with hypercholesterolemia and the metabolic syndrome (from the VYMET study). Am J Cardiol. 2009;103:1694-1702.

76. Goldberg RB, Guyton JR, Mazzone T, et al. Ezetimibe/simvastatin vs atorvastatin in patients with type 2 diabetes mellitus and hypercholesterolemia: the VYTAL study. Mayo Clin Proc. 2006;81: 1579-1588.

77. Winkler K, Jacob S, Müller-Schewe T, Hoffmann MM, Konrad T. Ezetimibe alone and in combination lowers the concentration of small, dense low-density lipoproteins in type 2 diabetes mellitus. Atherosclerosis. 2012;220:189-193.

78. Kotani K, Sakane N, Taniguchi N. Effect of ezetimibe on remnant-like particle cholesterol in subjects with metabolic syndrome. Med Princ Pract. 2012;21:134-138.

79. Tota-Maharaj R, Defilippis AP, Blumenthal RS, Blaha MJ. A practical approach to the metabolic syndrome: review of current concepts and management. Curr Opin Cardiol. 2010;25:502-512.

80. Baigent C, Keech A, Kearney PM, et al. Efficacy and safety of cholesterol-lowering treatment: prospective meta-analysis of data from 90,056 participants in 14 randomised trials of statins. Lancet. 2005;366: 1267-1278.

81. Guyton JR, Bays HE. Safety considerations with niacin therapy. Am J Cardiol. 2007;99:22C-31C.

82. Davidson MH, Armani A, McKenney JM, Jacobson TA. Safety considerations with fibrate therapy. Am J Cardiol. 2007;99:3C-18C.

83. Tuteja S, Pyrsopoulos NT, Wolowich WR, et al. Simvastatinezetimibe-induced hepatic failure necessitating liver transplantation. Pharmacotherapy. 2008;28:1188-1193.

84. Castellote J, Ariza J, Rota R, Girbau A, Xiol X. Serious drug-induced liver disease secondary to ezetimibe. World J Gastroenterol. 2008;14: 5098-5099.

85. Stolk MFJ, Becx MCJM, Kuypers KC, Seldenrijk CA. Severe hepatic side effects of ezetimibe. Clin Gastroenterol Hepatol. 2006;4: 908-911.

86. Brown WV. Safety of statins. Curr Opin Lipidol. 2008;19:558-562.

87. Kashani A, Sallam T, Bheemreddy S, Mann DL, Wang Y, Foody JM. Review of side-effect profile of combination ezetimibe and statin therapy in randomized clinical trials. Am J Cardiol. 2008;101: 1606-1613.

88. Kagan A, McGee DL, Yano K, Rhoads GG, Nomura A. Serum cholesterol and mortality in a Japanese-American population: the Honolulu Heart program. Am J Epidemiol. 1981;114:11-20.

89. Duncan RE, El-Sohemy A, Archer MC. Statins and cancer development. Cancer Epidemiol Biomarkers Prev. 2005;14:1897-1898.

90. Boudreau DM, Yu O, Johnson J. Statin use and cancer risk: a comprehensive review. Expert Opin Drug Saf. 2010;9:603-621.

91. Shepherd J, Blauw GJ, Murphy MB, et al. Pravastatin in elderly individuals at risk of vascular disease (PROSPER): a randomised controlled trial. Lancet. 2002;360:1623-1630.

92. Rossebø AB, Pedersen TR, Boman K, et al. Intensive lipid lowering with simvastatin and ezetimibe in aortic stenosis. N Engl J Med. 2008;359: $1343-1356$.
93. Peto R, Emberson J, Landray M, et al. Analyses of cancer data from three ezetimibe trials. N Engl J Med. 2008;359:1357-1366.

94. Howard BV, Roman MJ, Devereux RB, et al. Effect of lower targets for blood pressure and LDL cholesterol on atherosclerosis in diabetes: the SANDS randomized trial. JAMA. 2008;299:1678-1689.

95. Taylor AJ, Villines TC, Stanek EJ, et al. Extended-release niacin or ezetimibe and carotid intima-media thickness. $N$ Engl J Med. 2009;361: 2113-2122.

96. Stein EA. Additional lipid lowering trials using surrogate measurements of atherosclerosis by carotid intima-media thickness: more clarity or confusion? J Am Coll Cardiol. 2008;52:2206-2209.

97. Smilde TJ, van Wissen S, Wollersheim H, Trip MD, Kastelein JJ, Stalenhoef AF. Effect of aggressive versus conventional lipid lowering on atherosclerosis progression in familial hypercholesterolemia (ASAP): a prospective, randomised, double-blind trial. Lancet. 2001; 357:577-581

98. Toth PP, Maki KC. A Commentary on the implications of the ENHANCE (Ezetimibe and Simvastatin in Hypercholesterolemia Enhances Atherosclerosis Regression) Trial: Should ezetimibe move to the 'Back of the Line' as a therapy for dyslipidemia? J Clin Lipidol. 2008;2:313-317.

99. Simon T, Boutouyrie P, Gompel A, et al. Rationale, design and methods of the CASHMERE study. Fundam Clin Pharmacol. 2004;18: $131-138$

100. Fleg JL, Mete M, Howard BV, et al. Effect of statins alone versus statins plus ezetimibe on carotid atherosclerosis in type 2 diabetes: the SANDS (Stop Atherosclerosis in Native Diabetics Study) trial J Am Coll Cardiol. 2008;52:2198-2205.

101. Meaney A, Ceballos G, Asbun J, et al. The VYtorin on Carotid intimamedia thickness and overall arterial rigidity (VYCTOR) study. J Clin Pharmacol. 2009;49:838-847.

102. Blumenthal RS, Michos ED. The HALTS trial - halting atherosclerosis or halted too early? N Engl J Med. 2009;361:2178-2180.

103. Kastelein JJP, Bots ML. Statin therapy with ezetimibe or niacin in high-risk patients. $N$ Engl J Med. 2009;361:2180-2183.

104. Holme I, Boman K, Brudi P, et al. Observed and predicted reduction of ischemic cardiovascular events in the Simvastatin and Ezetimibe in Aortic Stenosis Trial. Am J Cardiol. 2010;105:1802-1808.

105. Fellström BC, Jardine AG, Schmieder RE, et al. Rosuvastatin and cardiovascular events in patients undergoing hemodialysis. $N$ Engl $J$ Med. 2009;360:1395-1407.

106. Wanner C, Krane V, März W, et al. Atorvastatin in patients with type 2 diabetes mellitus undergoing hemodialysis. N Engl J Med. 2005;353: $238-248$

107. Scarpioni R, Ricardi M, Melfa L, Cristinelli L. Dyslipidemia in chronic kidney disease: are statins still indicated in reduction cardiovascular risk in patients on dialysis treatment? Cardiovasc Ther. 2010;28: 361-368.

108. Cannon CP, Giugliano RP, Blazing MA, et al. Rationale and design of IMPROVE-IT (IMProved Reduction of Outcomes: Vytorin Efficacy International Trial): comparison of ezetimbe/simvastatin versus simvastatin monotherapy on cardiovascular outcomes in patients with acute coronary syndromes. Am Heart J. 2008;156:826-832.

109. Califf RM, Lokhnygina Y, Cannon CP, et al. An update on the IMProved reduction of outcomes: Vytorin Efficacy International Trial (IMPROVE-IT) design. Am Heart J. 2010;159:705-709.
Vascular Health and Risk Management

\section{Publish your work in this journal}

Vascular Health and Risk Management is an international, peerreviewed journal of therapeutics and risk management, focusing on concise rapid reporting of clinical studies on the processes involved in the maintenance of vascular health; the monitoring, prevention and treatment of vascular disease and its sequelae; and the involvement of

\section{Dovepress}

metabolic disorders, particularly diabetes. This journal is indexed on PubMed Central and MedLine. The manuscript management system is completely online and includes a very quick and fair peer-review system, which is all easy to use. Visit http://www.dovepress.com/ testimonials.php to read real quotes from published authors. 